young boys as part of the system of too rapid driving of immature minds. Mr. B. M. Neville had tried the plan of taking voltaic electricity early, and leading the class to the problems of electrolysis. The behaviour of electrolytes suggested the existence of discrete quantities or particles of electricity, whence the boys obtained the concept of a measurable static charge. Upon this concept the structure of electrostatics could be built. Several speakers took part in the discussion, of which the outcome appeared to us to be as follows:-Current electricity is attractive to boys, and it takes an unusually poor teacher to deprive it of its interest; electrostatics can be made very interesting by a very good teacher. As a rule, the current work is far more successful than the other. A weak spot in past teaching has been the link between current and static effects; it was felt that Mr. Ashford's demonstration would help members to strengthen that link. Supposing the first difficulty of the transition to be mastered, several of the subsequent difficulties would be in the same position whichever approach had been adopted, except for the important consideration that the boys, by previous current work, had gained some familiarity with, and confidence in discussing, the problems of potential difference, \&c. If boys had to leave school before finishing the electrical course, it was more profitable to them to have had the current electricity than the electrostatics, supposing time did not allow both to be taken.

The important question of the possibility of "formal training"-in the psychological sense of the term-was introduced by Mr. A. Vassall (Harrow) in a paper of remarkable lucidity. He advised science masters to study the recent work of psychologists, and took as a particular example the problem of formal training. $\mathrm{He}$ was led from his own experience to doubt the "faculty psychology" by which much of our present practice is usually justified, and found that general powers of observation are not necessarily increased by special training. A boy highly trained as an observer of chemical phenomena only develops his observational powers for chemical phenomena; there is no "overflow" which will increase his general powers of observation except where there is some identity. We must cultivate wide knowledge and interests, and pay more attention to the subject-matter of the curriculum and less to mental gymnastics. It seemed little less than a crime to use the lower or middle-school divisions simply as a training-ground for the later study of formal science when the majority of boys in the divisions are not proceeding to such later study. There is a marked tendency so to use them at present-e.g. there is too much weighing and mensuration, glass-working, and other chemical manipulation. These boys should work on broad linesin physics at such things as the electric installation of a house; in chemistry at real experiments in breathing, burning, and decay, and other topics of wide application. The ideal curriculum would give the boy (I) as much knowledge of certain subjects as is required for culture and æsthetics; (2) of other subiects only so much as will not sap his intellectual self-reliance by their being attempted beyond his capacity; (3) a special knowledge, when possible, of a subject or subjects which will be useful to him in his after-life.

Prof. Armstrong stated that he accepted neither the experiments of the psychologists nor their inferences. $\mathrm{He}$ was convinced that types of mind differed more than was zommonly recognised. An engineering, constructive mind could only be interested, for instance, in chemistry by appealing to it through topics closely in agreement with its own bias, e.g. through problems concerning the corrosion of metals. We must keep in mind man's experience through the ages. Man had been accustomed only to fight, to work, and to use his commercial instinct; and almost all modern education was alien to the experience of the race. We must make our instruction practical enough and simple enough for the majority of minds, and avoid the common tendency to postpone introducing a subject to too late in age. Dr. T. P. Nunn said that psychologists were quite alive to the present imperfections of their science, and all leaders in the subiect advised caution in the application of recent inferences. The idea that the mind was iike a photographic plate, the sensitiveness of which to all subjects could be increased by attention to one, was quite wro.ıg. None the less, there was a development beyond a NO. 2203 , VOL. 887 mere record of the actual thing observed. A student by observing gained self-reliance; he learned that he was capable of drawing a rational inference without depending on external authority; he learned that he must not be in a hurry if he wished to observe aright. These acquirements did increase a boy's power to behave duly and perform correctly in various situations. While listening to the discussion, which was well maintained, we could not help feeling that science teachers of all grades would gain much by a study of the papers on formal training which were read by Dr. Myers, Dr. Sleight, and Mr. C. L. Burt at the London County Council Conference of Teachers during the preceding week. They would gain a clearer idea of the present position of psychology, especially of the importance of the elements common to various mental performances.

We have brought together the above four subiects somewhat out of their order in the programme of the science masters' meeting, because they appear to manifest a common tendency. They all deal with the problem of suiting the subject-matter and the order of its presentation to the growing intelligence and developing interests of the boy. A few years ago the sequence of studies in the science side of the curriculum was determined by considerations of their logical order, and no one doubted that the logical order was the right one to follow. The new movement tends to make the logical order less dominant, and to determine the sequence rather by the psychological order of the boy's mental growth. We venture to put forward our personal impression of the direction in which, judged from the general attitude of the conferences, the science curriculum is evolving. Before doing so, we note with pleasure the action of the Headmasters' Conference with regard to Greek at entrance examinations, which was taken at the December (I9II) meeting.

The headmasters of the largest public schools have definitely committed themselves to action which shall relieve the preparatory schools from teaching Greek to little boys. This makes it possible for a boy during his school life to follow such a course as the following:(r) In the preparatory school a course of practical and seasonal nature-study with gradually increasing thoroughness and method; (2) in the lower school of the public school courses of, say, astronomy and plant physiology (as suggested in the paper by E. I. Lewis); (3) in the middle school a course of physics and chemistry, in which the utilitarian interest of the boys is utilised and made more and more scientific (cf. C. E. Ashford and A. Vassall), the quantitative side being well-developed, but not exclusively so. It is supposed that many boys will carry school science no further than this. For those who intend to pursue scientific study after school life there will be (4) a course of systematic study in physics, chemistry, and of ten biology. The work in this stage may best be treated by the method of the seminar, and considerable encouragement may well be given to the historical and philosophical aspects. It may even be wise to encourage theoretical speculation in order to inculcate habits of independent, self-reliant observation and reflection. Books of reference should be used, including French and German texts, and such works as Jevons's "Principles of Science", and Pearson's "Grammar of Science" should find readers. The suggestions for this stage appear to be in harmony with Sir Joseph Thomson's address.

The annual meeting of the Mathematical Association and the remainder of the science masters' programme will receive consideration in a subsequent article; but it may be stated at once that both meetings were well attended, and showed a growth in the area of effectiveness of the societies.

G. F. Daniell.

\section{THE PROTECTION OF ANCIENT}

\section{MONUMENTS.}

THE question of the protection of ancient monuments in this country has reached a new phase by a paper recently read by Sir Schomberg McDonell, secretary to the Office of Works, before the Society of Antiquaries. He referred to numerous cases, such as those of Stonehenge, the camp at Penmaenmawr, Meavy Bridge, Chichester Cross, the wall paintings of Tewkesbury Abbey, the proposed restoration of Carnarvon Castle, as instances 
in which much damage had been, or was likely to be, caused to national monuments by reckless interference. To meet this evil, he suggested the establishment of an advisory committee, composed of men eminent in archæology and public life, with representatives of the leading archrological societies, the British Museum, nominees of the Archbishops of Canterbury and York, and of the Ecclesiastical Commissioners.

It should be the duty of the committee, when satisfied that any monument of national importance was in danger, to recommend to the First Commissioner of Works that the custody of it should be assumed by the nation. On receipt of this report, the First Commissioner, if he thought fit, should move his Majesty to declare by an Order of Council that the monument was one of national importance, and was accordingly transferred to the custody of the First Commissioner. The scheme should not, he suggested, apply to dwelling houses in actual occupation, but in the case of important ecclesiastical buildings now in use he proposed that no scheme of restoration should be carried out until the plans had been passed by the advisory committee. Until the question has been more fully discussed, it would be premature to pass an opinion upon it. But, on the whole, it seems to offer a suitable remedy for a very important and growing evil.

\section{NOTES ON MUSEUMS AND MENAGERIES.}

I N The Field of December 9, I9I, there is an illustrated account of the new buildings recently added by the Hon. Walter Rothschild to his zoological museum at Tring, these additions considerably more than doubling the size of the original structure. As extended, the building forms three sides of a square, of which, when viewed from the front, the central transverse portion and the right wing are new. The exhibition galleries are throughout lighted by windows placed high up in the walls, so that comparatively little direct sunlight falls on the cases, this being screened, when necessary, by scarlet blinds, which are claimed by the owner to prevent all the ill-effects of actinism. The new exhibition galleries are fitted along each outer wall with a continuous series of glass and steel cases, to feet in height, and constructed on a modification of the principle adopted in the zoological museum at Dresden, these being stated to be absolutely dust-proof, A similar but wider series of cases, divided by a longitudinal partition of wood, occupies the middle line of each of the new galleries. The new buildings include also a library, containing 30,000 volumes, forming about 6000 separate works, workrooms, studies, \&c.

With characteristic promptitude and energy, $\mathrm{Mr}$. Rothschild has already arranged his specimens (which were previously crowded together) in the new cases, so that naturalists and the general public are able to appreciate the vast extent and excellent mounting of this really marvellous collection. The mounting of the larger mammals, as well as of many of the birds, has been in recent years mainly executed by Rowland Ward, Ltd. For a notice of some of the specimens in the exhibition galleries our readers may be referred to the article already cited.

The La Plata Museum forms the subject of an article by Dr. E. H. Ducloux, the vice-director, in the Revue générale des Sciences of November I5. That institution, which the writer considers to be the most important of its kind in South America, is the work of a single individual, Dr. H. P. Moreno; and to write the history of the former is practically the same as to write a biography of the latter, who was the first director. The museum was established by the Provincial Government in 1889 on the base of an anthropological and archæological museum founded in 1877 . In its foundation Dr. Moreno had to wage an uphill fight against indifference, and sometimes hostility, in high quarters; but he eventually succeeded in getting the present palatial building erected, and brought together the wonderful collection of Argentine and Patagonian extinct vertebrates which has rendered the institution deservedly famous throughout the scientific world. It was the aim and intention of its founder that the functions of the museum should include not only science, but to a certain extent art; and, as at present constituted, its NO. 2203, VOL. 887 organisation embraces geography, geology, mineralogy, palæontology, botany, zoology and anatomy, anthropology (including ethnography and linguistics), and chemistry and pharmacy, while a special annexe is devoted to a school of design.

The statute of September 25, 1905, which organised the National University of La Plata- of which, according to the author, the already existing municipal scientific institutions ought to form the foundation-will, it is hoped, open to the museum a wider horizon, and remove it from the verge of penury which, under any other direction, would eventually bring about its ruin. The article contains several illustrations, one of which shows part of the wonderful series of the giant armadillos, or glyptodonts, of the Pampean epoch.

In the November number of The Zoologist Captain Stanley Flower concludes his notes on zoological institutions in various parts of Europe recently visited by himself. Dealing in this contribution with Stuttgart and Vienna, he remarks that, among the forty-eight institutions inspected, "the Tiergarten at Doggenburg, near Stuttgart, would be the most profitable to visit. The site is small, the collection is small, and the animals are of no great value, but the arrangement is such that everything is exhibited to its best advantage. The lover of animals who visits Doggenburg will carry away with him the impression that he has seen but few species, but these all carefully provided for and happy; the schoolchild wil have seen the principal types of the vertebrate fauna of Europe, and enough exotic ones to excite his further interest; the casual visitor will not know exactly what he has or has not seen, but will feel satisfied that he has had his money's worth.",

\section{CARBOHYDRATE FORMATION IN PLANT FOLIAGE.}

A VALCABLE and interesting contribution to the study of the formation of carbohydrates in the foliage leaf is contained in a paper, by Mr. John Parkin, published in The Biochemical Journal (vol, vi., part i.). In order to simplify the case as much as possible and to reduce the conflicting factors to a minimum, the snowdrop (Galanthus nivalis, L.) was chosen as the plant to be investigated, as in a previous research the author had shown that in no case is starch or inulin to be detected in the mesophyll of the leaf. It was therefore probable that maltose would be absent in the leaf also, and the research would be thus narrowed down to studying the relationship between cane sugar, dextrose, and lævulose under different conditions. The object aimed at in the beginning was to test Brown and Morris's view, enunciated in 1893 , that cane sugar is the first product of carbon-assimilation in plants.

It was found, actually, that maltose is always absent from the snowdrop leaf, so that it appears probable that maltose, when present in foliage leaves, is a hydrolysis product of starch. The quantity of total sugars in the snowdrop leaf is considerable, being from $20-30$ per cent. of the dry weight in leaves actively assimilating. The amount of sugar increases from above downwards in a single leaf, and, at the same time, the ratio of the cane sugar to the hexoses (dextrose and lævulose) diminishes. The proportion of cane sugar to the hexoses decreases as the season advances, that is to say, in the early part of the season there is more cane sugar in proportion to reducing sugar than later, the comparison being made between leaves gathered about the same period of the day. During any single day the percentage of hexose sugars in the leaf remains fairly constant, no matter at what hour out of the twenty-four the leaves may be examined. That of the cane sugar, however, fluctuates greatly, increasing during the day and decreasing during the night. Further, leaves detached and insolated contain decidedly more cane sugar than their controls, but the quantity of hexose sugar remains nearly the same. The lævulose, as a rule, is in excess of the dextrose, irrespective of the time of day or the period of the spring the leaves are picked for analysis.

In discussing these results, the author inclines to the view that cane sugar is, as suggested by Brown and Morris, the first sugar formed in the leaf. But they are not entirely incompatible with the idea that dextrose is the 